\title{
Repeated evolution of asymmetric genitalia and right-sided mating behavior in the Drosophila nannoptera species group
}

\author{
Andrea E. Acurio ${ }^{1,2}$, Flor T. Rhebergen ${ }^{3,4}$, Sarah Paulus ${ }^{1}$, Virginie Courtier-Orgogozo ${ }^{1}$ and Michael Lang ${ }^{1 *}$ (D)
}

\begin{abstract}
Background: Male genitals have repeatedly evolved left-right asymmetries, and the causes of such evolution remain unclear. The Drosophila nannoptera group contains four species, among which three exhibit left-right asymmetries of distinct genital organs. In the most studied species, Drosophila pachea, males display asymmetric genital lobes and they mate right-sided on top of the female. Copulation position of the other species is unknown.

Results: To assess whether the evolution of genital asymmetry could be linked to the evolution of one-sided mating, we examined phallus morphology and copulation position in D. pachea and closely related species. The phallus was found to be symmetric in all investigated species except D. pachea, which displays an asymmetric phallus with a right-sided gonopore, and D. acanthoptera, which harbors an asymmetrically bent phallus. In all examined species, males were found to position themselves symmetrically on top of the female, except in $D$. pachea and D. nannoptera, where males mated right-sided, in distinctive, species-specific positions. In addition, the copulation duration was found to be increased in the nannoptera group species compared to closely related outgroup species.
\end{abstract}

Conclusion: Our study shows that gains, and possibly losses, of asymmetry in genital morphology and mating position have evolved repeatedly in the nannoptera group. Current data does not allow us to conclude whether genital asymmetry has evolved in response to changes in mating position, or vice versa.

Keywords: Phallus asymmetry, Drosophila nannoptera species group, One-sided mating position, Copulation behavior

\section{Background}

Changes in behavior are thought to play important roles in animal evolution [1-3]. How new behaviors evolve and how they are encoded in the genome is little understood. New behaviors can initiate secondary evolutionary shifts in morphology, physiology or ecology ("behavioral drive") [1-9], for example when they bring an organism into contact with new environmental factors. Behavior can also prevent evolutionary changes because plasticity in behavior might enable individuals to adjust for changed environmental conditions [10-12]. Other investigations suggest that behavior and morphology are both subject to selection and that their responses to changes

\footnotetext{
* Correspondence: michael.lang@ijm.fr

'Institut Jacques Monod, CNRS, UMR 7592, Université Paris Diderot, Sorbonne

Paris Cité, 15 rue Hélène Brion, 75013 Paris, France

Full list of author information is available at the end of the article
}

in the environment are perhaps independent $[13,14]$, or that behavior could simultaneously impede and drive evolutionary diversification of different characters [12, 15, 16]. So far, it appears that the effects of behavioral changes on the evolution of morphological traits cannot be generalized and that they require case-specific assessments.

The evolution of left-right asymmetric genitalia in insects is a case where morphology was proposed to have evolved in response to changes in mating behavior [17]. Asymmetric genitalia are observed in many species and phylogenetic studies indicate that they have evolved multiple times independently from symmetric ancestors $[18,19]$. While most extant insect species copulate with the male being on top of the female abdomen, the ancestral mating position in insects is inferred to be a configuration with the female on top of the male $[18,20,21]$.

(c) The Author(s). 2019 Open Access This article is distributed under the terms of the Creative Commons Attribution 4.0 International License (http://creativecommons.org/licenses/by/4.0/), which permits unrestricted use, distribution, and 
The extant male-on-top configuration has likely evolved multiple times in insects [20]. Such changes in mating position probably altered the efficiency of male and female genital coupling, and may have led to the evolution of genital asymmetries to optimize the coupling of genitalia [17]. Furthermore, these changes in position may have been driven by male-male competition, or by sexual conflict between males and females.

The nannoptera species group belongs to the genus Drosophila and consists of four described species that feed and breed on rotten pouches of columnar cacti of the genus Stenocereus and Pachycereus in Northern and Central America [22-24]. These species are particularly interesting to study the evolution of genital asymmetry because distinct genital structures were identified to be asymmetric in three out of the four described species of this group. Drosophila acanthoptera males have an asymmetric phallus, $D$. pachea males have a pair of asymmetric external lobes with the left lobe being approximately 1.5 times longer than the right lobe [25, 26], and in the sister species $D$. wassermani males have a pair of asymmetric anal plates (cerci) [25]. In contrast, no asymmetries are known in the fourth described species D. nannoptera [27]. The four species separated about 3$6 \mathrm{Ma}$ and lineage-specific changes likely led to the distinct and elaborated asymmetries in each species [28]. Interestingly, $D$. pachea mates in a right-sided copulation position where the male rests on top of the female abdomen with its antero-posterior midline shifted about 6-8 degrees to the right side of the female midline [26, 29]. This one-sided mating posture is associated with asymmetric coupling of female and male genitalia during copulation, with the male genital arch being rotated about 6 degrees towards the female's right side. Apart from our previous investigations of the $D$. pachea copulation position [26, 29], little is known about mating positions in other Drosophila species. In Diptera, several mating positions are known and all involve a symmetric alignment of male and female genitalia. Male and female genitalia are usually inversely positioned relative to each other with the dorsal surface of the aedeagus (phallus) contacting the ventral side of the female reproductive tract [30]. Drosophila melanogaster, D. simulans and $D$. sechellia were reported to adopt such a symmetric copulation posture, with the male aligned along the female midline [31-33]. A one-sided mating position was generated artificially in $D$. melanogaster by unilateral ablation of a long bristle located on the genital claspers [31]. In any case, no data is currently available regarding mating positions of the closely related species of $D$. pachea.

The observation of a right-sided mating posture and asymmetric male genitalia in D. pachea led us to wonder whether morphological asymmetry in the nannoptera group species might have evolved in response to the evolution of one-sided mating [17]. We therefore decided to investigate copulation position and aedeagus asymmetry in species closely-related to D. pachea, and to reconstruct their most likely evolutionary history.

\section{Results}

The phallus of $D$. pachea is asymmetric

The shape of the aedeagus/phallus of $D$. pachea has not been described previously. We examined the aedeagus of two dissected $D$. pachea males using scanning electron microscopy (SEM) and found that both were strikingly asymmetric (Fig. 1). Aedeagi were strongly bent, dorsally flattened and pointed at the dorsal tip. Their ventral region bore two ventrally pointing asymmetric spurs, one positioned apically, the other sub-apically. The gonopore was positioned dorso-apically on the right side of the aedeagus. The aedeagal parameres broke off during dissection and were not visualized. In order to corroborate the SEM observations, we dissected and examined 10 aedeagi of $D$. pachea males using light microscopy. Apical and subapical spurs, as well as a right-sided gonopore, were consistently observed in all preparations $(n=$ 10, Additional file 1: Figure S1). Our results indicate that the $D$. pachea phallus is directionally asymmetric (Fig. $2 b)$.

\section{Aedagus asymmetry is observed in $D$. acanthoptera but not in $D$. nannoptera, $D$. machalilla and $D$. bromeliae}

We compared aedeagus shapes in several species that are closely related to $D$. pachea (Fig. 2). As previously described [27], the aedeagus of $D$. acanthoptera was found to be asymmetrically bent $(n=10)$. Two asymmetric spurs were found at the ventral apical tip of the aedeagus, with the right spur being consistently longer than the left spur (Fig. 2e, Additional file 1: Figure S2, Additional file 2). However, in contrast to $D$. pachea, no dorso-apical gonopore was observed on the right side of the apex. Aedeagi of D. nannoptera males (Fig. 2k, Additional file 1: Figure S3, Additional file 2) were found to be symmetric $(n=15)$. The ventral side of the apex revealed two apical elongations with slightly variable lengths at the left and right side $(n=15$, Additional file 1: Figure S3, Additional file 2). The variation in length was not directional and thus considered to reflect random fluctuating asymmetry. The ventral tip of the aedeagus of D. machalilla (atalaia species group) $(n=10)$ displayed two lateral hooks (Fig. 2n, Additional file 1: Figure S4, Additional file 2), of the same length on both sides. The aedeagus of $D$. bromeliae showed two lateral symmetric ridges $(\mathrm{n}=10)$ (Fig. 2q, Additional file 1: Figure S5, Additional file 2). In summary, aedeagus asymmetry was only observed in $D$. pachea and $D$. acanthoptera, 


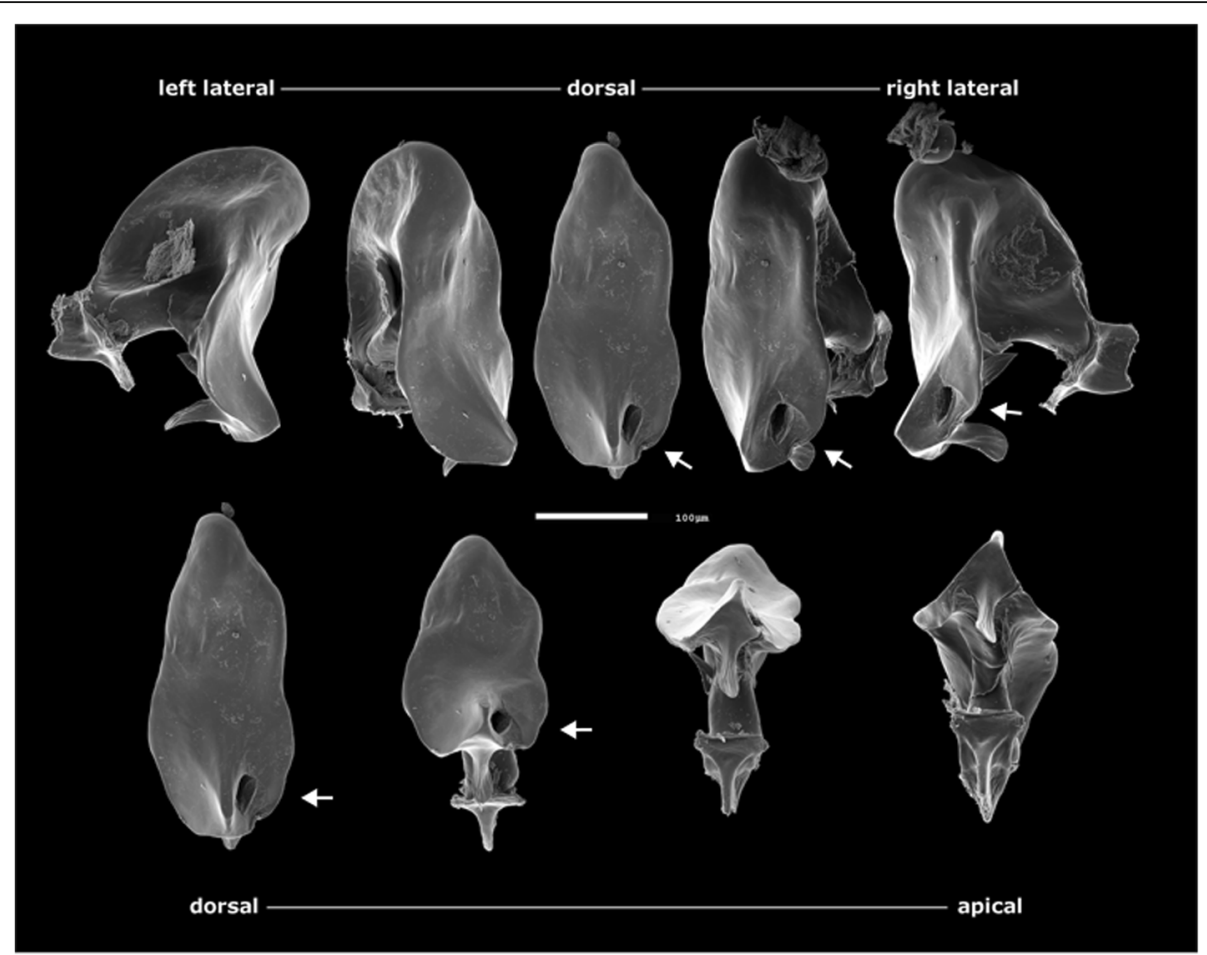

Fig. 1 The aedeagus of male Drosophila pachea is asymmetric. SEM images of a single phallus in lateral-dorsal and dorsal-apical view. Note the asymmetric position of two subapical spurs, located on the ventral side of the aedeagus, and the asymmetric position of the gonopore. The white arrows point to the gonopore. The scale bar is equivalent to $100 \mu \mathrm{m}$

and distinct phallus structures were found to be asymmetric in these species.

\section{D. pachea and $D$. nannoptera males mate right-sided}

The position of the male during copulation has not been described for any of the closely related species of $D$. pachea. In this study, we assessed copulation postures in $D$. pachea and nine related species: D. acanthoptera and D. nannoptera (sister species of D. pachea), D. machalilla and D. bromeliae (representatives of close outgroup lineages), D. buzzatii and D. mojavensis (members of the repleta species group), as well as representatives of other Drosophila species groups (D. tripunctata, D. willistoni and D. melanogaster). Phylogenetic relationships between the ten studied species were estimated with a Bayesian phylogeny (Additional file 1: Figure S6) based on a previously published sequence dataset [28], supplemented with publicly available sequence data (this study) for D. tripunctata and D. willistoni (Additional file 3). The obtained phylogeny is congruent with previous findings [28] that D. nannoptera, D. acanthoptera and $D$. pachea form a monophyletic group with a short internode branch length between the split of the $D$. nannoptera lineage and the separation of $D$. acanthoptera and D. pachea. Also, D. machalilla and D. bromeliae form two close outgroup lineages of the nannoptera clade [28, 34, 35], followed by the repleta group species D. buzzatii and D. mojavensis [28].

For each species, we introduced a single virgin female and a single virgin male into a circular mating chamber and recorded the couple until copulation ended or for 45 min when no copulation was detectable. We obtained 315 movies, of which 111 were used for assessing courtship duration, 146 for copulation duration and 124 for copulation posture analysis (Additional file 4). Most movies were discarded because no copulation occurred or individuals had damaged wings or legs (all reasons listed in Additional file 4). As previously described [3638 ], copulation duration varied significantly among species (ANOVA, df $1=9$, df $2=136, F=73.38, p<2 \mathrm{e}-16$ ) (Table 1). We could reproduce a previously reported trend that copulation duration in nannoptera group species was remarkably long compared to $D$. mojavensis and D. buzzatii of the repleta group, with copulation duration of $88.49 \mathrm{~min} \pm 35.18 \mathrm{~min}$ for $D$. acanthoptera, $29.58 \pm 7.86 \mathrm{~min}$ for $D$. pachea and $11.9 \pm 4.2 \mathrm{~min}$ for $D$. nannoptera (mean \pm standard deviation (SD)). In comparison, copulation duration of $D$. buzzatii $1.79 \pm 0.65$ min and D. mojavensis $2.3 \pm 0.35$ min (mean $\pm \mathrm{SD}$ ) of the repleta species group was shorter and similar to $D$. machalilla $2.28 \pm 0.53 \mathrm{~min}$ and D. bromeliae $0.92 \pm 0.28$ min (mean \pm SD) (Table 1$)$. 


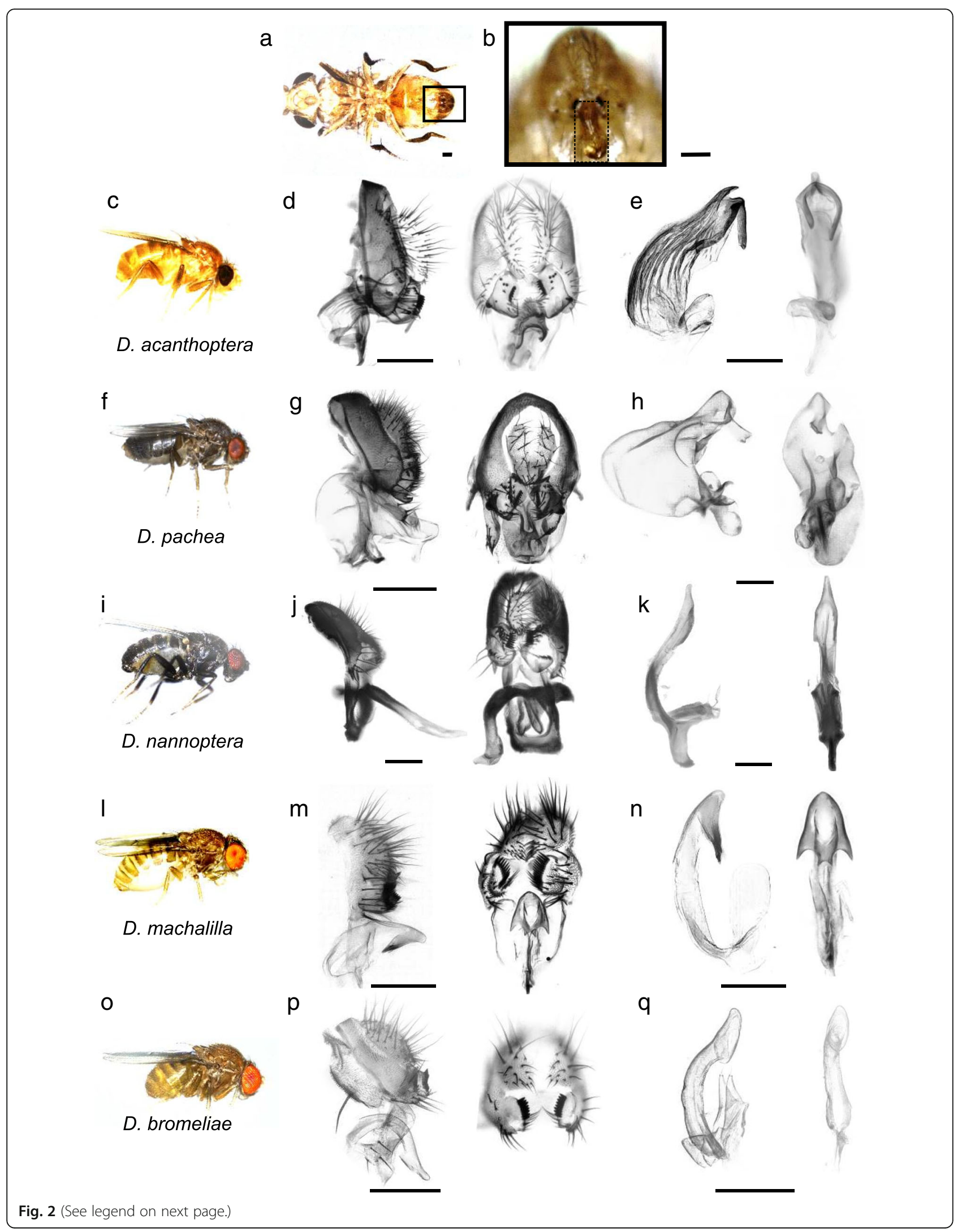


(See figure on previous page.)

Fig. 2 Genital and aedeagus shapes in D. pachea and closely related species. External genitalia and aedeagus shapes are compared across closely related species of $D$. pachea. Aedagus asymmetries are only found in D. acanthoptera and D. pachea. (a) ventral view of a D. acanthoptera male. The black frame indicates the position of male genitalia and the box with a dashed frame $(\mathbf{b})$ shows a magnification with an erected penis. (c, $\mathbf{f}, \mathbf{i}$, I, o) Lateral views of male specimens and male genitalia of D. acanthoptera, D. pachea, D. nannoptera, D. machalilla, and D. bromeliae, respectively. $(\mathbf{d}, \mathbf{g}, \mathbf{j}, \mathbf{m}, \mathbf{p})$ Male terminalia in lateral and posterior view. $(\mathbf{e}, \mathbf{h}, \mathbf{k}, \mathbf{n}, \mathbf{q})$ Aedeagus in lateral and ventral view. The scale bar is $100 \mu \mathrm{m}$

To assess mating posture, we calculated the angle between a line drawn through the female head midline and the female scutellum tip and a second line drawn through the male head midline and the female scutellum tip (Additional file 1: Figure S7a). The angle was set positive when male head lies on the right side of the female and negative when on the left. The camera view relative to the fly couple position within the mating cell may affect the measured angle in each experiment but the sign of the average mating angle taken from different recordings for each species should accurately reflect the one-sidedness of the male mating position. As a consequence, we expected a one-sided copulation position to produce a consistent positive or negative distribution of angle values, while symmetric mating positions should result in an angle distribution around zero.

To compare mating angles between species, it is necessary to examine copulation postures at the same corresponding time point during copulation. At copulation start, the male position on top of the female was found to be greatly variable between couples, even within a single species, so this time point was not considered appropriate for our comparative analysis. Since copulation duration varies greatly between species, finding another comparable time point across species was not trivial. We subdivided copulation into two phases, an initial phase where the male is on top of the female abdomen but consistently moving legs and abdomen, and a second phase when the male maintains an invariant position relative to the female, which can sometimes walk or move its legs (Additional file 1: Figure S6). The "settling time point" is defined as the time point between the first and second phase, when the male adopts an invariant position relative to the female. For our cross-species analysis we chose to assess copulation angle at two time points: (1) right after the male had settled into an initial invariant copulation position (the settling time point) and (2) at $10 \%$ of elapsed time between the settling time point and the end of copulation (10\% stable copulation time point). These two time points were assumed to represent moments during copulation that are comparable between species. For species with a mean copulation duration $>2.5 \mathrm{~min},>15 \mathrm{~min}$ or $>60 \mathrm{~min}$, we also measured the angles every $2.5 \mathrm{~min}, 5 \mathrm{~min}$ or $10 \mathrm{~min}$, respectively. This allowed us to follow mating postures of each species over the course of copulation.

Significant one-sided mating positions were observed in D. pachea and D. nannoptera, both at the settling time point and at the $10 \%$ stable copulation time point (Fig. 3a,b, Table 2). No significant one-sided copulation postures were detected in D. acanthoptera and the other seven tested species including D. melanogaster (Fig. 3a,b).

Over the course of copulation, mating angles continued to range over zero for $D$. melanogaster and $D$. acanthoptera (Fig. 3c,d), indicating a relatively steady symmetric copulation position without any left- or right-sidedness. Similar to previous investigations [26, 29], $D$. pachea revealed right-sided angles that were highest at the beginning of copulation at $0-10 \mathrm{~min}$ after settling (Fig. 3e). At later time points, the angles tended to range over zero. In $D$. nannoptera, mating angles

Table 1 Courtship and copulation duration

\begin{tabular}{|c|c|c|c|c|c|c|}
\hline species & $\begin{array}{l}\text { courtship duration } \\
\text { [min] (mean } \pm \text { SD) }\end{array}$ & range $[\mathrm{min}]$ & $n$ & $\begin{array}{l}\text { copulation duration } \\
\text { [min] (mean } \pm \text { SD) }\end{array}$ & range $[\mathrm{min}]$ & $n$ \\
\hline D. acanthoptera & - & - & - & $88.49 \pm 35.18$ & $38.85-144.32$ & 12 \\
\hline D. pachea & $4.67 \pm 3.91$ & $0.17-12.37$ & 18 & $29.58 \pm 7.86$ & $7.33-42.63$ & 21 \\
\hline D. nannoptera & $1.89 \pm 3.25$ & $0.05-12.67$ & 15 & $11.9 \pm 4.2$ & $4.03-20.1$ & 21 \\
\hline D. machalilla & $1.97 \pm 3.44$ & $0.08-11.85$ & 13 & $2.28 \pm 0.53$ & $1.07-3.55$ & 18 \\
\hline D. bromeliae & $2.07 \pm 2.4$ & $0.23-8.37$ & 10 & $0.92 \pm 0.28$ & $0.65-1.73$ & 12 \\
\hline D. mojavensis & $1.56 \pm 2.71$ & $0.13-5.63$ & 4 & $2.3 \pm 0.35$ & $1.83-2.57$ & 4 \\
\hline D. buzzatii & $2.87 \pm 5.26$ & $0.08-18.87$ & 15 & $1.79 \pm 0.65$ & $1.13-3.42$ & 17 \\
\hline D. tripunctata & $5.17 \pm 5.98$ & $0.68-13.82$ & 4 & $33.34 \pm 9.54$ & $20.47-42.15$ & 4 \\
\hline D. willistoni & $5.72 \pm 5.39$ & $0.53-14.65$ & 5 & $16.88 \pm 2.58$ & $13.9-21.55$ & 6 \\
\hline D. melanogaster & $13.48 \pm 8.9$ & $2.55-40.23$ & 27 & $13.83 \pm 4.33$ & $7.57-24.55$ & 31 \\
\hline
\end{tabular}




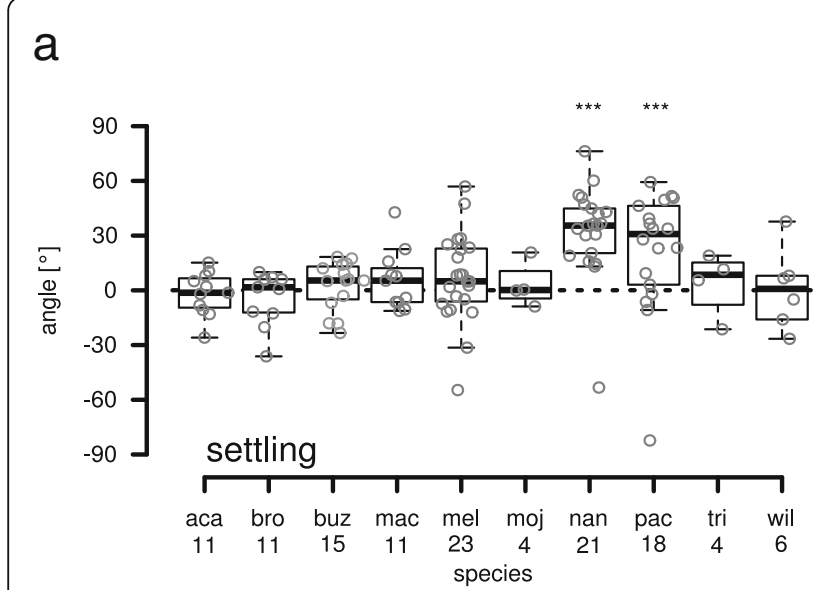

b

C

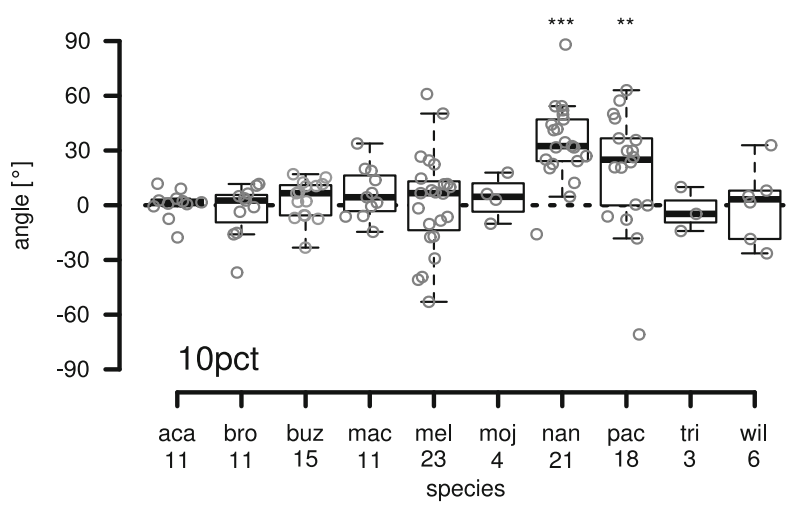

d
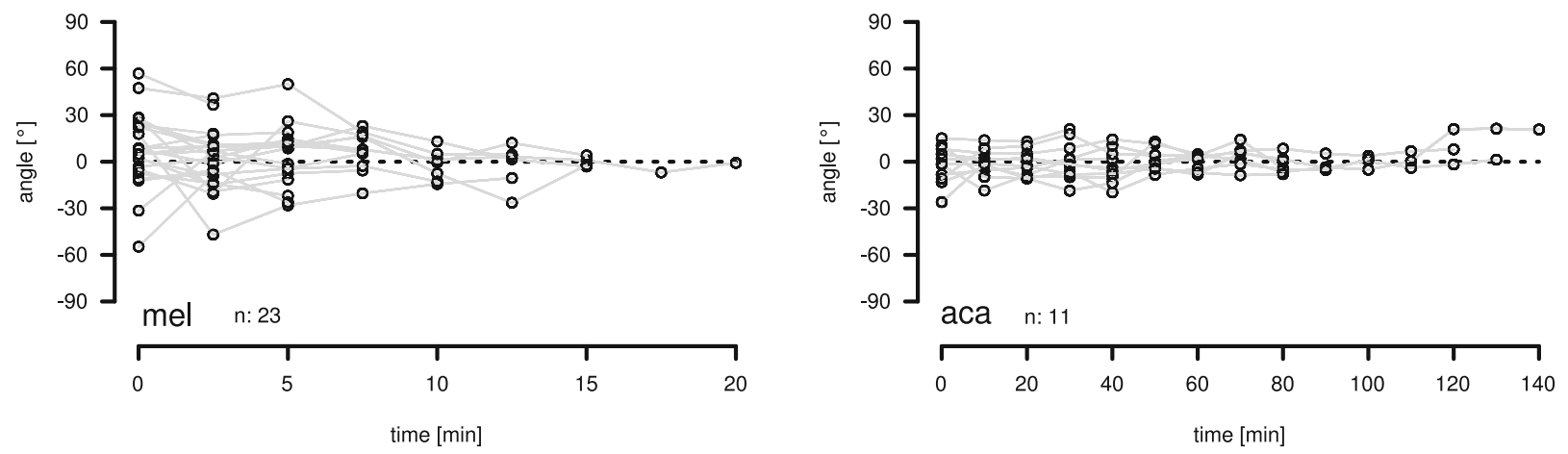

e

f
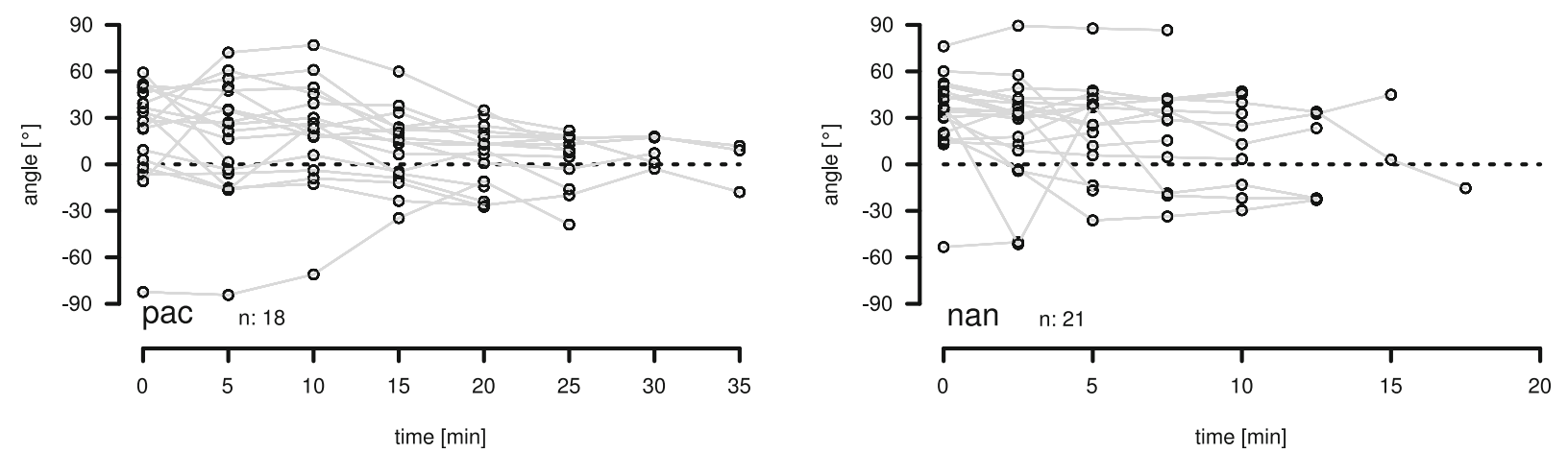

Fig. 3 The copulation position of D. nannoptera and D. pachea is asymmetric. Copulation angles of $D$. pachea couples and of nine related Drosophila species; aca: D. acanthoptera, bro: D. bromeliae, buz: D. buzzatii, mac: D. machalilla, mel: D. melanogaster, moj: D. mojavensis, nan: D. nannoptera, pac: D. pachea, tri: D. tripunctata, wil: D. willistoni. (a,b) Copulation angle at the settling time point (settling, see material and methods) and at the $10 \%$ stable copulation time point (10pct), respectively. Stars indicate significant rejection of the null hypothesis: angle $=0$ (Table 2, GLM fit angle species **: $p<0.001,{ }^{* * *}: p<0.0001$ ). Numbers below each boxplot indicate the number of observations. The dashed lines indicate an angle of zero degrees. (c-e) Copulation angles over the course of copulation of D. melanogaster (mel), D. acanthoptera (aca), D. pachea (pac) and D. nannoptera (nan). $\mathrm{n}$ indicates the number of observations. Grey lines connect points obtained from the same copulation couple over time. The dashed lines indicate an angle of zero degrees

tended to be right-sided throughout copulation (Fig. 3f). In summary, $D$. pachea and $D$. nannoptera revealed a right-sided copulation posture whereas all the other tested species displayed a symmetric mating posture.
Male $D$. nannoptera tilt to the right side of the female abdomen during copulation

To further investigate the right-sided copulation posture in $D$. nannoptera and better observe the male position 
Table 2 Test for one-sided mating positions. Fit: GLM (angle species), family = "gaussian", hypothesis: angle =0, Bonferroni corrected $p$-values

\begin{tabular}{|c|c|c|c|c|c|c|c|c|c|}
\hline \multirow[t]{2}{*}{ species } & \multicolumn{3}{|l|}{ settling } & \multicolumn{3}{|c|}{$\begin{array}{l}10 \% \text { stable copulation time point replicate } \\
\text { measurement } 1\end{array}$} & \multicolumn{3}{|c|}{$\begin{array}{l}10 \% \text { stable copulation time point replicate } \\
\text { measurement } 2\end{array}$} \\
\hline & est. contrast & $z$ value & $\mathrm{p}$ & est. contrast & $z$ value & $\mathrm{p}$ & est. contrast & $z$ value & $\mathrm{p}$ \\
\hline D. acanthoptera & -1.9105 & -0.282 & 1 & 0.5919 & 0.091 & 1 & -0.4980 & -0.075 & 1 \\
\hline D. pachea & 21.4011 & 4.048 & 0.000517 & 18.8120 & 3.704 & 0.00212 & 17.8498 & 3.449 & 0.00564 \\
\hline D. nannoptera & 32.5346 & 6.646 & $3.00 \mathrm{e}-10$ & 34.4231 & 7.321 & $2.46 \mathrm{e}-12$ & 35.0479 & 7.314 & $2.60 \mathrm{e}-12$ \\
\hline D. machalilla & 5.7585 & 0.851 & 1 & 6.5023 & 1.001 & 1 & 8.2219 & 1.242 & 1 \\
\hline D. bromeliae & -3.9911 & -0.590 & 1 & -2.9702 & -0.457 & 1 & -0.7399 & -0.112 & 1 \\
\hline D. mojavensis & 3.0034 & 0.268 & 1 & 4.2370 & 0.393 & 1 & 6.3650 & 0.580 & 1 \\
\hline D. buzzatii & 2.4878 & 0.430 & 1 & 3.0853 & 0.555 & 1 & 1.2320 & 0.217 & 1 \\
\hline D. tripunctata & 3.6189 & 0.323 & 1 & -2.9770 & -0.239 & 1 & -5.4349 & -0.429 & 1 \\
\hline D. willistoni & 0.7288 & 0.080 & 1 & 0.4118 & 0.047 & 1 & 0.6928 & 0.077 & 1 \\
\hline D. melanogaster & 6.6156 & 1.414 & 1 & 1.6010 & 0.356 & 1 & 0.7997 & 0.175 & 1 \\
\hline
\end{tabular}

relative to the female dorso-ventral midline, we filmed the couples from a frontal perspective (Additional file 1: Figure S8). In particular, we assessed the inclination of the male body relative to the female dorso-ventral axis by measuring the angle P4-P5-P6, with $\mathrm{P} 4$ as the medial most dorsal edge of the female head (often visible by the ocelli), P5 being the most ventral medial position of the female head (the female proboscis) and P6 as the medial most dorsal edge of the male head (often visible by the ocelli) (Additional file 1: Figure S8).

D. nannoptera mating positions were on average strikingly right-sided (Additional file 1: Figure S8), with a considerable variation of observed angles, ranging from slightly left- to strongly inclined right-sided $\left(-8.42^{\circ}-\right.$ $57.7^{\circ}$ ) over the course of copulation. Left-sided angles were only observed during the first two minutes of copulation. On average, the male tended to initially adopt a right-sided copulation posture with an angle of $10.36^{\circ} \pm 6.88^{\circ}$ (mean $\left.\pm \mathrm{SD}\right)(n=25)$ between 0 and $1 \mathrm{~min}$ after copulation start (Table 3 ). Over the course of copulation, the angle then increased to $27.16^{\circ} \pm 10.81^{\circ} \quad(n=29)$ between 3 and $4 \mathrm{~min}$ after copulation start (Table 3 ), which was visible by an inclination of the male head towards the female's right side. This tilt-movement was not observed in $D$. pachea, where all males remained on top of the female abdomen [29]. We therefore conclude that $D$. pachea and D. nannoptera adopt distinct copulation postures, even though both of them are right-sided.

\section{Discussion}

Phallus asymmetries differ between $D$. pachea and $D$. acanthoptera

The currently published data suggest that genital asymmetries are rare among Drosophila species. The genus Drosophila encompasses over 1500 described species [39] and only 8 species have been shown without doubt to display an asymmetric phallus: D. marieaehelenae and $D$. hollisae of the flavopilosa group [40, 41], D. asymmetrica and $D$. quinarensis of the guarani group [42, 43], $D$. endobranchia of the canalinea group [44], D. acumina$n u s$ and D. freilejoni of the onychophora group [27, 45, 46] and the nannoptera group species D. acanthoptera [27]. Genital asymmetry might be more widespread than what is reported in the literature across Drosophila, as certain species are only described based on a few specimens, and subtle asymmetric characters might have been overlooked and interpreted as fluctuating variation between left and right sides. Here, we compared aedeagus morphology of at least 10 specimens of five different species that belong to the nannoptera species group and closely related species. We did not detect aedeagus asymmetry in the tested species outside of the nannoptera

Table 3 D. nannoptera frontal mating angles

\begin{tabular}{lll}
\hline time interval after cop. Start [min] & angle (mean \pm SD) & $\mathrm{n}$ \\
\hline $0-1$ & $10.36 \pm 6.88$ & 25 \\
$1-2$ & $15.46 \pm 8.82$ & 29 \\
$2-3$ & $23.44 \pm 12.15$ & 29 \\
$3-4$ & $27.16 \pm 10.81$ & 27 \\
$4-5$ & $29.1 \pm 11.62$ & 25 \\
$5-6$ & $28.97 \pm 11.92$ & 21 \\
$6-7$ & $32.48 \pm 8.29$ & 13 \\
$7-8$ & $26.44 \pm 10.24$ & 5 \\
$8-9$ & $23.21 \pm 11.88$ & 4 \\
$9-10$ & $24.7 \pm 13.66$ & 3 \\
$10-11$ & $18.65 \pm 14.03$ & 2 \\
$11-12$ & $8.07 \pm N A$ & 1 \\
\hline
\end{tabular}

The mean estimates for each time interval were calculated with average values when multiple measurement points were available for a given experiment 
species group and found that within the nannoptera group only $D$. acanthoptera and $D$. pachea but not $D$. nannoptera reveal striking left-right asymmetries (Fig. 4). We did not evaluate aedeagus asymmetry of $D$. wassermani, as this species is not available for examination and our attempts to catch specimens in the wild were not successful (see materials and methods). Asymmetries differed between $D$. pachea and $D$. acanthoptera. Whereas ventral spurs on the $D$. pachea aedeagus were apart from each other, with one being apical and the other subapical, the aedaegus of $D$ acanthoptera had a pair of apical spurs that differed in length. In addition, the gonopore was visible and right-sided in $D$. pachea while it was not visible in $D$. acanthoptera. Our results thus highlight that the asymmetric phallus structures of $D$. pachea and $D$. acanthoptera are derived morphologies that have little in common and diversified independently after the split of the two species about 3-6 Ma ago [28]. It is impossible to infer whether the asymmetries observed in both species derived from a pre-existing asymmetric phallus in their ancestor or if asymmetry evolved de novo in both lineages.

The outer genitalia (epandrium) has been reported to be asymmetrical in $D$. pachea (where the left lobe is longer than the right lobe $[25,26]$ and in $D$. wassermani (where the right anal plate is larger than the left one [25]). Our inspection of a few dissected epandria of $D$. nannoptera, D. acanthoptera and D. machalilla revealed no obvious asymmetry (Fig. 2). However, a quantitative comparison remains to be done to confirm the absence of asymmetry in the epandrium of these species.

\section{Long copulation duration is specific to the nannoptera group species}

We observed that nannoptera species copulated considerably longer than any representative species of the close outgroup lineages (Fig. 4). This trend was previously reported by Pitnick and Markow (1991) [36, 37], where the authors compared copulation duration of nannoptera group species with repleta group and other species. Here we included two additional closely related species, D. machalilla and D. bromeliae, and observed that their copulation durations were relatively short. Our observations therefore indicate that a long copulation duration is specific to the nannoptera group.

\section{Right-sided mating positions differ between $D$. pachea and $D$. nannoptera}

We assessed copulation postures of D. pachea and a range of related species to track the extent of right-sided mating position in the nannoptera group. Two aspects of copulation behavior made cross-species comparisons difficult. First, copulation duration was extremely diverse and ranged from less than a minute in $D$. bromeliae to more than two hours in $D$. acanthoptera. Second, the movements of the male and female during copulation varied between species. In $D$. melanogaster and $D$. willistoni, we observed vigorous movements of the male during copulation accompanied by female hindleg kicking. These phases were interrupted by periods without movements. In contrast, males of most other species initially moved upon mounting the female and then settled into an invariant copulation posture relative to the female.

At the two measured time points during the initial stable copulation period (settling time point, 10\% stable copulation time point), the angle between the male midline and the female midline was distributed symmetrically around zero, indicating a symmetric mating position in all tested species except $D$. pachea and $D$. nannoptera. Our previous data from $D$. pachea $[26,29]$ was re-analyzed in this study with a

\begin{tabular}{|c|c|c|c|c|c|c|}
\hline & Aedagus & $\begin{array}{l}\text { External } \\
\text { Genitalia }\end{array}$ & $\begin{array}{l}\text { Mating } \\
\text { Position }\end{array}$ & $\begin{array}{c}\text { Mating } \\
\text { Duration }\end{array}$ & $\begin{array}{l}\text { Sperm } \\
\text { Length }\end{array}$ & $\begin{array}{l}\text { Sperm } \\
\text { Storage }\end{array}$ \\
\hline D. pachea & AS & AS (lobes) & right-sided & $30 \mathrm{~min}$ & 16.6 & $\mathrm{sp}$ \\
\hline D. wassermani & nd & AS (anal plates) & nd & nd & 4.5 & $\mathrm{sp}$ \\
\hline LD. acanthoptera & AS & $\mathrm{s}$ & $\mathrm{s}$ & $88 \mathrm{~min}$ & 5.8 & $\mathrm{sp}$ \\
\hline LD. nannoptera & S & S & right-tilted & $12 \mathrm{~min}$ & 15.7 & rec \\
\hline L_ machalilla & $\mathrm{s}$ & $\mathrm{s}$ & $\mathrm{s}$ & $<3 \min$ & nd & nd \\
\hline D. bromeliae & $\mathrm{s}$ & $\mathrm{s}$ & $\mathrm{s}$ & $<3 \min$ & nd & $\mathrm{sp}+\mathrm{rec}$ \\
\hline D. mojavensis & S & S & $\mathrm{s}$ & $<3 \min$ & 1.9 & rec \\
\hline D. melanogaster & $\mathrm{s}$ & s & $\mathrm{s}$ & $14 \mathrm{~min}$ & 1.9 & $s p+r e c$ \\
\hline
\end{tabular}

Fig. 4 Evolution of sexual characters in the nannoptera species group. The cladogram was established based on the phylogeny of this study (Additional file 1: Figure S6), combined with data from Lang et al. (2014) [28]. AS, asymmetric states; S, symmetric states; nd, not determined, sp, spermathecae; rec, female seminal receptacle 
different measurement approach and led to the same conclusion as our earlier reports. In addition, we found that $D$. nannoptera adopts a right-sided mating position with angle values that were slightly higher than in D. pachea (Fig. 3). Assessment of homology of behaviors is difficult compared to morphological characters, because Owen's position criterion for homology [47] does not exist for behavioral traits. Observation of similar behaviors does not necessarily mean common descent [6]. Our precise examination of the mating position of $D$. nannoptera from a frontal perspective revealed that $D$. nannoptera males strongly tilt to the female's right side during copulation, a behavior that is not observed in D. pachea $[26,29]$. Therefore, mating postures can be regarded as distinct between the two species. Interestingly, a comparable tilting behavior during copulation was observed in experiments with $D$. pachea males that had surgically modified external genital lobes [29]. Male lobes are considered to be important in grasping the female abdomen beneath the oviscapt valves and to keep $D$. pachea upright on the female abdomen. A hypothetical scenario is thus that the ancestral mating position in shared ancestor of the two species may have been right-tilted but the evolution of asymmetric external lobes in $D$. pachea led to a derived right-sided copulation posture, which is upright. Alternatively, right-sided mating position may have evolved independently in the two lineages leading to $D$. pachea and D. nannoptera. In all scenarios, at least two evolutionary changes in mating position must be considered to account for the distinct, species-specific right-sided mating positions in the nannoptera group.

\section{Asymmetry in mating position and in phallus have evolved in different branches of the nannoptera group phylogeny}

Across the nannoptera group, we find no striking correspondence between right-sided mating posture and asymmetric male genitalia. For example, $D$. acanthoptera has an asymmetric aedeagus but mates in a symmetric overall posture. Conversely, no directional asymmetry is detected in the male (external and internal) genitalia of $D$. nannoptera, but males adopt a right-sided copulation posture (Fig. 4). Based on our phylogeny, D. nannoptera presents the earliest branching lineage within the nannoptera group. In this sense, right-sided mating postures could have originated earlier during evolution than asymmetric morphologies and may have been lost in $D$. acanthoptera. However, the internode branch length between the split of the $D$. nannoptera lineage and the separation of $D$. acanthoptera and $D$. pachea is short and statistical support is weak [28]. Thus, phylogenetic relationships within the nannoptera group remain to be resolved and it is more appropriate to regard all nannoptera species as sister species.

So far, we conclude that both right-sided copulation behavior and asymmetric male genitalia evolved within the nannoptera species group and that diversification of both traits have involved lineage-specific evolutionary changes. They may have evolved by modifications of pre-existing right-sided mating behavior and/or asymmetric genital morphologies already present in the ancestor. Alternatively, they can have appeared de novo in each extant lineage.

One-sided mating and asymmetric phallus are correlated with giant sperm and female sperm storage, respectively Asymmetric genital morphology and right-sided mating behavior may also be associated with other characters that are special to the nannoptera species group. $D$. pachea and D. nannoptera are among the Drosophila species that produce the longest (giant) sperm [48, 49] (Fig. 4). The association of right-sided mating with giant sperm production actually holds better than with asymmetric male genital morphology because $D$. acanthoptera has an asymmetric aedeagus but has relatively small sperm [48] and mates in a symmetric overall posture (Fig. 4). Again, a specific one-sided mating posture might be necessary for optimal transfer of giant sperm. Examining mating postures in Drosophila species which harbor even longer sperm (D. bifurca $58 \mathrm{~mm}, D$. kanekoi $24 \mathrm{~mm}, D$. hydei $23 \mathrm{~mm}, D$. eohydei $18 \mathrm{~mm}$ ) [50, 51] would be interesting to test further the possible association between sperm length and one-sided mating.

The species $D$. pachea, $D$. acanthoptera and $D$. wassermani are also special in the way the female stores sperm after copulation (Fig. 4). They are the only Drosophila species that store sperm exclusively inside the spermathecae but not in the seminal receptacle as most other species [49]. In contrast, D. nannoptera stores sperm exclusively inside the seminal receptacle [49]. Morphological phallus asymmetry is thus observed in those species that reveal exclusive sperm storage in the spermathecae. It would be interesting to collect male specimens of $D$. wassermani to analyze their phallus shapes to test this trend. In any case, it is hard to generalize from our observations as only three species are concerned.

\section{Evolution of left-right asymmetric genitalia and one-sided mating in the nannoptera group}

During $D$. pachea copulation, the male is on top on the female and oriented towards the female right side [29]. Since the male gonopore is located on the right side of the aedeagus (this study), the opening of the male reproductive tract during copulation is expected not to be 
aligned with the female opening. In D. nannoptera, male structures are symmetric but the male and female openings are probably also unaligned because of the tilted mating position. One-sided copulatory behavior and asymmetric genital morphology can thus both contribute to asymmetric complexing of male and female structures in an additive or compensatory way. The evolution of mating posture and genital asymmetry might therefore both be driven by selection on the sterical characteristics of the complex of male and female genitalia. Why would asymmetric male-female genitalia complexing evolve? As mentioned above, asymmetric complexing might facilitate the transfer of giant sperm into the female tract. Another possibility would be because of sexual conflict between males and females [52-54], as asymmetric alignments of the male and female reproductive structures might overcome internal barriers in the female uterus that otherwise prevent sperm entry. Asymmetric genital complexing could also be a stimulus for the female to preferentially store or use sperm, thereby driving the evolution of mating position and genital asymmetry by cryptic female choice $[53,55,56]$. For example, males of the fly Dryomyza anilis tap the female external genitalia shortly after insemination with a pair of genital claspers, which can be symmetric or asymmetric [57, 58]. Males with asymmetric small claspers have higher fertilization success compared to males with large symmetric ones, suggesting that asymmetric male tapping can bias sperm distribution in the spermathecae [59]. Females of the nannoptera group store sperm exclusively in the spermathecae, except for $D$. nannoptera females that only use the receptacle [49]. Such rapid evolution of post-copulatory sperm processing is indicative of sexual selection and cryptic female choice. The exact underlying mechanisms are unknown but it is possible that they also contributed to the evolution of asymmetric structures and one-sided copulation behaviors. Future studies of the positioning of the phallus gonopore inside of the female uterus and of sperm transfer during copulation in the various nannoptera group species would be helpful to test the various scenarios.

\section{Conclusion}

Phallus asymmetries were identified in $D$. pachea and $D$. acanthoptera of the nannoptera species group and distinct structures were observed to be asymmetric in both species. An increased copulation duration was found to be specific to nannoptera group species and was not observed in the closely related outgroup species $D$. machalilla and D. bromeliae. Right-sided mating positions were detected in $D$. pachea and D. nannoptera and were found to be distinct between them. Our data does not allow us to conclude whether the evolution of the right-sided copulation position may have promoted the evolution of genital asymmetry, or vice versa. Our results nevertheless indicate that asymmetry in genital morphology and in copulation behavior have evolved through multiple evolutionary steps in the nannoptera group, revealing a complex history of sexual trait changes, maybe in relationship with the evolution of giant sperm and unique sperm storage in the nannoptera group.

\section{Methods}

\section{Fly sampling and maintenance}

An isofemale stock of Drosophila machalilla was established from a collection of A. A. in December 2015 at San Jose Beach (GPS coordinates: 01 ${ }^{\circ} 13^{\prime} 46.4^{\prime \prime} \mathrm{S}, 80^{\circ} 49^{\prime}$ 14.6 "W) Ecuador, using a modified version of the fly traps described in [60]. Our baits contained rotten pieces of the columnar cactus Armatocereus carwrightianus and yeast solution. The D. machallila stock was raised on standard Drosophila medium (60 g/L brewer's yeast, $\quad 66.6 \mathrm{~g} / \mathrm{L} \quad$ cornmeal, $\quad 8.6 \mathrm{~g} / \mathrm{L}$ agar, $5 \mathrm{~g} / \mathrm{L}$ methyl-4-hydroxybenzoate and $2.5 \% \mathrm{v} / \mathrm{v}$ ethanol) and a piece of fresh Opuntia ficus-indica (prickly pear opuntia) or Hylocereus undatus (dragon fruit) in the medium. The isofemale stock was raised for two generations before experiments started and it was maintained for a total of 36 generations.

We also intended to collect $D$. wassermani in August 2016 in Oaxaca, Mexico. Six localities were sampled based on previous records: Reserva de la Biosfera Tehuacan-Cuicatlan (GPS coordinates $18^{\circ} 11^{\prime} 21.30^{\prime \prime} \mathrm{N}$, 97 14' 51.7” W), Huajuapan de Leon $\left(17^{\circ} 48^{\prime} 25.6^{\prime \prime} \mathrm{N}, 97^{\circ}\right.$ 14' 56.7” W), San Luis del Rio (1646'30“ N, 96¹0' 49.9” W), and four sites along the Carretera Internacional 190: kilometer stones $\mathrm{Km} 73$ (16²' $57.2^{\circ}$ “ N, 96¹9’41.9” W), $\mathrm{km} 89\left(16^{\circ} 40^{\prime} 41.3^{\prime \prime} \mathrm{N}, 96^{\circ} 14^{\prime} 41.7^{\prime \prime} \mathrm{W}\right), \mathrm{km} 102$ (16 $46^{\circ}$ $\left.11.3^{\prime \prime} \mathrm{N}, 96^{\circ} 11^{\prime} 32.4^{\prime \prime} \mathrm{W}\right)$ and $\mathrm{km} 111\left(16^{\circ} 39^{\prime} 48.4^{\prime \prime} \mathrm{N}, 96^{\circ}\right.$ $\left.07^{\prime} 31.8^{\prime \prime} \mathrm{W}\right)$. We used banana traps, cactus baits that contained rotten organ pipe cactus Stenocereus prionosus and mixed food traps that additionally contained banana and yeast. Besides the invasive species Zaprionus indianus and cosmopolitan species $D$. melanogaster and $D$. simulans, we identified several species of the repleta group, about 100 individuals of $D$. nannoptera, three males of $D$. wassermani and one female of $D$. acanthoptera. Unfortunately, we were not successful in establishing iso-female strains from $D$. nannoptera and $D$. acanthoptera.

All other stocks were retrieved from the San Diego Drosophila Species Stock Center or were provided by Jean David (Additional file 1: Table S1). Flies were maintained at $25{ }^{\circ} \mathrm{C}$, except for $D$. melanogaster, D. tripunctata and $D$. willistoni, which were either maintaind at $22{ }^{\circ} \mathrm{C}$ or $25{ }^{\circ} \mathrm{C}$ (details in Additional file 4). Flies were kept in vials with $10 \mathrm{~mL}$ of standard Drosophila food 
medium (see above) inside incubators with a $12 \mathrm{~h}$ light: $12 \mathrm{~h}$ dark photo-periodic cycle combined with a $30-\mathrm{min}$ linear illumination change between light $(1080 \mathrm{~lm})$ and dark $(0 \mathrm{~lm})$. For maintenance of $D$. pachea, we mixed standard Drosophila food medium in the food vial with $40 \mu \mathrm{L}$ of $5 \mathrm{mg} / \mathrm{mL}$ 7-dehydrocholesterol (dissolved in ethanol) [61].

\section{SEM analysis of the $D$. pachea aedeagus}

Virgin males of at least 14 days after hatching from the pupa were transferred into a $2 \mathrm{~mL}$ reaction tube, snap frozen in liquid nitrogen and stored in ethanol at $-20^{\circ}$ C. For dissection, frozen and fixed males were placed in $80 \%$ ethanol at room temperature and the aedeagus was dissected out with fine needles. Tissues were dried using an EM CPD300 automated critical point dryer (Leica) and mounted on aluminium stubs with the distal end facing upwards and coated with platinum/palladium (20 $\mathrm{nm})$. Each aedeagus was SEM-imaged with a JSM-7500F field emission scanning electron microscope (Jeol) at 270x magnification.

\section{Analysis of aedeagus asymmetry by light microscopy} The terminal segments of the male abdomen were picked out with fine forceps and boiled for $10 \mathrm{~min}$ in two drops of $30 \% \mathrm{KOH}$. Genital parts were further dissected on a microscope slide (Thermo Scientific Menzel) in a drop of water using $0.1 \mathrm{~mm}$ Minutien Pins (Fine Science Tools) under the stereo-microscope K-500 (VWR). Dissected structures were mounted in pure glycerol on $1.5 \mathrm{~mm}$ concave microscope slides (Marienfeld). Images were acquired with a light microscope VHX2000 (Keyence) equipped with a zoom lens VH-Z100UR/W at 350-550 fold magnification. For storage, male genitalia were mounted in DMHF medium on microscope slides (Entomopraxis).

\section{Phylogenetic analysis}

We used data of eight species from a multi-locus dataset of Lang et al. (2014) [28], and added corresponding sequences for $D$. willistoni and D. tripunctata (Additional file 1: Table S2, Additional file 3, BEAST input file in DRYAD). For D. tripunctata, only mitochondrial data was available at GenBank (https://www.ncbi.nlm.nih. gov/nucleotide/) and missing data was annotated by '?'. Phylogenetic analysis was performed in BEAST [62] according to the settings described in Lang et al. (2014) [28]. Markov-Chain Monte-Carlo (MCMC) runs were performed with a chain length of $10^{7}$ generations and recorded every 1000 generations. MCMC output analysis was carried out using TreeAnnotator [62] and the tree was visualized and edited with FigTree (http://tree.bio. ed.ac.uk/software/figtree/). We chose a strict molecular clock and set priors for most recent common ancestors according to the divergence estimates of Lang et al. (2014) [28] for the splits of $D$. nannoptera - D. pachea $3.7 \pm 1.5 \mathrm{Ma}, D$. bromeliae - D. pachea $8 \pm 3 \mathrm{Ma}$. The divergence estimate for all analyzed species was set to 40 $\pm 5 \mathrm{Ma}[63]$.

\section{Copulation recording}

Emerged flies (0-14 h) were anesthetized with $\mathrm{CO}_{2}$, separated according to sex and transferred into food vials in groups of either 5 females or 5 males using a Stemi 2000 (Zeiss) stereo microscope and a $\mathrm{CO}_{2}$-pad (Inject+Matic sleeper). Flies were maintained at $22^{\circ} \mathrm{C}$ or $25^{\circ} \mathrm{C}$ until they reached sexual maturity (Additional file 1: Table S1). Males of D. bromeliae, D. melanogaster, D. pachea and $D$. nannoptera were isolated into single vials for at least two days before the experiment was performed. For video recording, one male and one female were introduced with a self-made fly aspirator by mouth suction into a circular plastic mating cell with a diameter of 10 $12 \mathrm{~mm}$, a depth of $4 \mathrm{~mm}$ and a transparent 1-mm Plexiglas cover [26]. For copulation recording of $D$. acanthoptera, flies were let to initiate copulation in a food vial and were then rapidly transferred to the mating cell.

Movies were recorded in a climate controlled chamber [26] at 22 or $25 \pm 0.1^{\circ} \mathrm{C}$ and $60 \%$ or $85 \% \pm 5 \%$ humidity (Additional file 4). Flies were filmed from above using digital microscope cameras 191,251-62 (Conrad), DigiMicro Profi (DNT) or MIRAZOOM MZ902 (OWL). Movies were recorded with the program GUVCVIEW (version 0.9.9) GTK UVC or Cheese (version 3.18.1) (https://wiki.gnome.org/Apps/Cheese) at a resolution of 800 X 600 pixels on a Linux Ubuntu operating system. Movies were recorded until copulation ended or for at least $45 \mathrm{~min}$ when no copulation was detectable. After movie recording, flies were dissected or stored in ethanol at $-20^{\circ} \mathrm{C}$.

\section{Multiple species mating position analysis}

Each movie name consisted of a three-letter abbreviation for the species filmed, an additional two-digit number that also indicated the species and a two-digit number for each respective experiment. Movies were analyzed with the video editor OpenShot 1.4.3 (Open Shot Studios, Texas, USA). Courtship start, copulation start, the settling time point and the end of copulation were annotated manually by two different persons, except for movies of $D$. pachea and $D$. melanogaster, which were annotated only by one person (Additional file 4). Courtship was defined to start when the male displayed at least three consecutive typical courtship behaviors, such as tapping the female, following the female's abdomen, licking the female oviscapt or the ground beneath the female abdomen, wing rowing ( $D$. melanogaster) or other wing vibrations [64]. Courtship was defined to end with the start of copulation, when a 
male started to mount the female abdomen. Only cases where the male remained mounted on the female for at least $15 \mathrm{~s}$ were counted as copulation starts. Copulation was defined to end when the male had completely descended from the female abdomen with the forelegs detached from the female dorsum and female and male genitalia being separated. As mentioned above, the male moved its legs and abdomen for a certain time period (considered as the settling phase) until adopting an invariant abdomen posture at the settling time point (Additional file 1: Fig. S6, Additional file 4). The remaining copulation period was defined as the stable copulation period (Additional file 1: Figure S6). In fact, this period was often interrupted by periods of vigorous movements in $D$. melanogaster, D. tripuncata and D. willistoni. In the other species, males remained rather invariant on the female abdomen after the settling time point.

We video-recorded 315 movies, of which 111 were used for assessing courtship duration (Additional file 4). Reasons for discarding 204 movies for courtship duration measurements were: wrong handling of the camera or the software, damaged files: 4; incomplete recording of courtship: 43; fly leg or wing damaged: 27; no copulation after $45 \mathrm{~min}$ of experiment start: 129; wing damaged and incomplete recording of courtship: 1. A total of 146 movies were used for the analysis of copulation duration. Reasons for discarding 169 movies for copulation duration measurements were: wrong handling of the camera or the software, damaged files: 4, incomplete recording of copulation: 7 , fly leg or wing damaged: 27 , no copulation after $45 \mathrm{~min}$ of experiment start: 129; multiple reasons: 2 (Additional file 4). From these 146 movies, we had to exclude 22 movies for the assessment of the copulation posture because landmark positions could not be observed. This was mainly due to couples being recorded from the ventral view. As a result, 124 experiments were used for assessment of the copulation posture (Additional file 4). One additional movie was discarded for posture assessment at the $10 \%$ stable copulation time point because the female head was not in the camera field of view.

Movie names were replaced by a seven-digit random number (Additional file 5) so that mating postures were quantified in a blind fashion with respect to the species name. Time points for position analysis (Additional file 1: Figure S6, Additional file 4) were calculated with a custom $\mathrm{R}$ script and exported values were used as an input for a bash script to extract images from each movie at particular time points with avconv (libav tools, https://www.libav.org).

The angle was measured using three landmarks on the female and male body: the anterior tip of the female head along its mid-line (P1), the distal tip of the female scutellum (P2) and the most posterior medial point of the male head (P3) (Additional file 1: Figure S7a). In cases where images were too dark, positions of P1 and P3 were approximated as the anterior and posterior mid distances between the eyes and the position of the scutellum tip (P2) was approximated by the medial dorsal point at the body constriction observed between the third thoracic and first abdominal segment. Position landmarks were placed manually on each image using imageJ and data analysis was done using R. Briefly, coordinates (Additional file 6) were rotated and scaled, so that all $\mathrm{P} 1$ points were superimposed and all $\mathrm{P} 2$ points as well (Additional file 1: Fig. S7b-k). The angle P1-P2-P3 (Additional file 1: Figure S7a) was used to measure one-sidedness of mating positions (Fig. 3). Repeatability of landmark positioning was assessed by two independent rounds of coordinate acquisition for all species at one specific time point during copulation, the $10 \%$ stable copulation time point (see text) $(2 \times 124$ images). Variation in angle estimates was found to be attributable mostly to individual images and not to replicate measurement (ANOVA, linear model: angle image + replicate, image: $\mathrm{df} 1=122, \mathrm{df} 2=123, \mathrm{~F}=87.174$, $p<2 \mathrm{e}-16$, replicate: $\mathrm{df} 1=1, \mathrm{df} 2=244, \mathrm{~F}=0.077, p=$ 0.782 ).

Hypothesis testing was performed in $\mathrm{R}$ to compare mating postures across species (Fig. 3) with the null hypothesis: angle $=0$, using the functions glm for generalized linear model fits, and glht to derive estimated contrasts.

\section{Analysis of the $D$. nannoptera copulation posture}

Flies were reared and isolated before copulation as described above. One female and one male were $\mathrm{CO}_{2}$ anesthetized and transferred onto a white plastic support (mating cap) and were caged with a transparent plastic cylindrical $25 \mathrm{~mm} \times 7 \mathrm{~mm}$ cap. Once courtship was observed, mating caps were put on a motorized horizontally turning stage $(0-30 \mathrm{rpm})$ (grinding stone 8215, Dremel) in front of a camera MIRAZOOM MZ902 (OWL) and copulation was recorded with the camera being put into an optimized frontal view towards the female head by rotating or turning the mating cap. The transparent cap was optionally removed once copulation had started. The yield of informative experiments with these settings was poor as we performed 167 mating experiments but only 29 experiments were informative for our data analysis (Additional file 7, reasons for discarding the experiments are listed). Images were extracted with avconv (see above) every $15-30 \mathrm{~s}$ or when the flies were visible in a frontal view. We measured the inclination of the male body relative to the female dorso-ventral axis by using three landmarks: P4 as the medial most 
dorsal edge of the female head (often visible by the ocelli), P5 being the most ventral medial position of the female head (the female proboscis) and P6 as the medial most dorsal edge of the male head (often visible by the ocelli) and measuring the angle between the lines drawn through P4-P5 and P5-P6 (Additional file 1: Figure S8, Additional file 8).

\section{Additional files}

\begin{abstract}
Additional file 1: Supplementary Figures and Tables. Figure S1 The aedeagus of $D$. pachea is asymmetric. Figure S2. The aedeagus of $D$. acanthoptera is asymmetric. Figure $\mathbf{S 3}$. No asymmetry is detected in the aedeagus of $D$. nannoptera. Figure S4. No asymmetry is detected in the aedeagus of $D$. machalilla. Figure S5. No asymmetry is detected in the aedeagus of D. bromeliae. Figure S6. Courtship and copulation duration in D. pachea and related species. Figure S7. Multi-species mating position measurements. Figure S8. D. nannoptera tilts to the right side of the female abdomen. Table S1 Species Resources, Table S2 GenBank Accession Numbers of the phylogeny dataset. (PDF $2543 \mathrm{~kb}$ )
\end{abstract}

Additional file 2: Length measurements at the left and right sides of the ventral aedeagus tip of $D$. acanthoptera, D. nannoptera, D. machalilla and D. bromeliae (CSV $9 \mathrm{~kb}$ )

Additional file 3: Multilocus DNA sequence dataset for the molecular phylogeny shown in Additional file 1: Figure S6. (PDF $59 \mathrm{~kb}$ )

Additional file 4: Multi-species analysis of courtship and copulation periods, shown in Additional file 1:: Figure S6. (CSV $69 \mathrm{~kb}$ )

Additional file 5: Randomization of experiment names for the multispecies mating position analysis. Original names and random number substitutes are listed for each movie. (CSV $9 \mathrm{~kb}$ )

Additional file 6: Landmark position measurements, used to calculate angle values for the multi-species mating position analysis, shown in Fig. 3. (CSV $101 \mathrm{~kb}$ )

Additional file 7: Copulation times of couples filmed for the position analysis of $D$. nannoptera from a frontal perspective, shown in Additional file 1: Figure S8. (CSV $15 \mathrm{~kb}$ )

Additional file 8: Angle measurements for the position analysis of $D$. nannoptera from a frontal perspective, shown in Fig. 3. (CSV $41 \mathrm{~kb}$ )

\section{Abbreviations}

ANOVA: Analysis of Variance, statistics; df: degrees of freedom; df1: degrees of freedom, numerator; df2: degrees of freedom, denominator; F: F-value; GPS: global positioning system; Ma: million years; MCMC: Markov-Chain Monte-Carlo; p: probability; SD: standard deviation; SEM: scanning electron microscopy; t: t-value

\section{Acknowledgements}

We are grateful to Sadjo Sidikou and Pierre Quevreux for movie recordings, to Bertie Joan van Heuven and Menno Schilthuizen for assistance and interpretation of SEM analysis and to Martina Manns for discussions of $D$. nannoptera mating positions. We greatly thank Álvaro Barragán, Violeta Rafael and Santiago Palacios for their help in the field work made in Ecuador (Research Permit No.003-15 IC-FAU-DNB/MA), Therese Markow and Alejandro Oceguera-Figueroa for their help with fly collections in Mexico, Jean David for Drosophila laboratory strains and Alexandre Peluffo for help with the statistical analysis.

\section{Funding}

This work was supported by the CNRS and by a grant of the European Research Council under the European Community's Seventh Framework Program (FP7/2007-2013 Grant Agreement no. 337579) given to Virginie Courtier-Orgogozo. FTR was financed by a Kees Bakker Award, awarded by the Stichting Professor Dr. K. Bakker Fonds. The funding body had no role in any activities regarding the study including design, sampling procedure, analysis, interpretation of the data and writing the manuscript.

\section{Availability of data and materials}

The data sets supporting the results of this article are available in the DRYAD repository, https://doi.org/10.5061/dryad.5h1q6mc

\section{Authors' contributions}

$\mathrm{ML}$ and $\mathrm{VCO}$ designed the experiments, AA collected fly specimen, AA, SP and $\mathrm{ML}$ recorded fly copulation, AA performed light microscopy analysis of Drosophila male genitalia, FTR performed SEM analysis of $D$. pachea male genitalia. ML, AA and SP analyzed the movie datasets, ML and VCO wrote the manuscript with AA. All authors have read and approved the manuscript.

Ethics approval and consent to participate

"Not applicable" --- This research focuses on invertebrate insects. There are no ethical considerations mentioned for these species according to EU Directive 86/609-STE123.

\section{Consent for publication}

"Not applicable".

\section{Competing interests}

The authors declare no competing financial interests.

\section{Publisher's Note}

Springer Nature remains neutral with regard to jurisdictional claims in published maps and institutional affiliations.

\section{Author details}

'Institut Jacques Monod, CNRS, UMR 7592, Université Paris Diderot, Sorbonne Paris Cité, 15 rue Hélène Brion, 75013 Paris, France. ²Present address: Charles Darwin Research Station, Charles Darwin Foundation, Santa Cruz Island, Galapagos, Ecuador. ${ }^{3}$ Naturalis Biodiversity Center, Darwinweg 2, 2333, CR, Leiden, the Netherlands. ${ }^{4}$ Present address: Institute for Biodiversity and Ecosystem Dynamics, University of Amsterdam, Science Park 904, 1098, XH, Amsterdam, the Netherlands.

Received: 14 February 2019 Accepted: 7 May 2019

Published online: 27 May 2019

\section{References}

1. Plotkin HC. The role of behavior in evolution: MIT press; 1988

2. E. Mayr, Animal Species and Evolution., Harvard Un. Cambridge, Massachusetts, 1963

3. West-Eberhard MJ. Developmental plasticity and evolution: Oxford University Press; 2003.

4. Baldwin JM. A new factor in evolution. Am Nat. 1896:30(354):441-51.

5. Hardy AC. The living stream: a restatement of evolution theory and its relation to the spirit of man. London: Collins; 1965.

6. E. Mayr, "Behavior and systematics," in Behavior and evolution, A. Roe and G. Simpson, Eds. Yale University Press New Haven, Connecticut, 1958, pp. 341-362.

7. E. Mayr, "Evolution after Darwin," in Evolution after Darwin, THE UNIVER., S. Tax, Ed. Chicago: The University of Chicago Press, 1960, pp. 349-380.

8. Wyles JS, Kunkel JG, Wilson AC. Birds, behavior, and anatomical evolution. Proc Natl Acad Sci. 1983:80(14):4394-7.

9. Wcislo WT. Behavioral environments and evolutionary change. Annu Rev Ecol Syst. 1989;20(1):137-69.

10. Bogert CM. Thermoregulation in reptiles, a factor in evolution. Evolution. 1949:3(3):195-211.

11. Coyne JA, Bundgaard J, Prout T. Geographic variation of tolerance to environmental stress in Drosophila pseudoobscura. Am Nat. 1983;122(4): 474-88.

12. Huey RB, Hertz PE, Sinervo B, Pagel AEM. Behavioral drive versus behavioral inertia in evolution: a null model approach. Am Nat. 2003; 161(3):357-66

13. Losos JB, Schoener TW, Spiller DA. Predator-induced behaviour shifts and natural selection in field-experimental lizard populations. Nature. Nov. 2004; 432:505.

14. Lapiedra O, Schoener TW, Leal M, Losos JB, Kolbe JJ. Predator-driven natural selection on risk-taking behavior in anole lizards. Science. 2018;360(6392): 1017-20. 
15. Duckworth RA. The role of behavior in evolution: a search for mechanism. Evol Ecol. 2009;23(4):513-31.

16. Muñoz MM, Losos JB. Thermoregulatory behavior simultaneously promotes and forestalls evolution in a tropical lizard. Am Nat. 2018;191(1):E15-26.

17. Huber BA. Mating positions and the evolution of asymmetric insect genitalia. Genetica. 2010;138(1):19-25.

18. Huber BA, Sinclair BJ, Schmitt M. The evolution of asymmetric genitalia in spiders and insects. Biol Rev. 2007;82(4):647-98.

19. Schilthuizen M. Something gone awry: unsolved mysteries in the evolution of asymmetric animal genitalia. Anim Biol. 2013;63:1-20.

20. Alexander RD. The evolution of mating behavior in arthropods. R entomol Soc London Symp. 1964;2:78-94.

21. McAlpine JF. Morphology and terminology_adults. In: Manual of Nearctic Diptera, Agricultur., vol. 1, no. 3, McAlpline JF, Peterson BV, Shewell GE, Teskey HJ, Vockeroth JR, wood DM; 1981. p. 9-63.

22. W. B. Heed, "The origin of Drosophila in the Sonoran Desert.," in Ecological Genetics and Evolution: The Cactus-Yeast-Drosophila Model System, Barker, J.S. F., Starmer, W.T., 1982, pp. 65-80.

23. W. J. Etges, W. R. Johnson, G. A. Duncan, G. Huckins, and W. B. Heed, "Ecological genetics of Cactophilic Drosophila.," in Ecology of Sonoran Desert Plants and Plant Communities., Tucson, Arizona: Robichaux, R., 1999, pp. 164-214.

24. W. B. Heed, "Origin of Drosophila of the Sonoran Desert Revisited: In Search of a Founder Event and the Description of a New Species in the Eremophila Complex.," in Genetics, Speciation, and the Founder Principle, Giddings, L.V., Kaneshiro, K.Y., Anderson, W.W., 1989, pp. 253-278.

25. S. Pitnick and W. Heed, "New Species of Cactus-breeding Drosophila (Diptera: Drosophilidae) in the Nannoptera Species group," Ann Entomol Soc Am, vol. 87, no. 3, pp. 307-310, Aug. 1994.

26. M. Lang and V. Orgogozo, "Distinct copulation positions in Drosophila pachea males with symmetric or asymmetric: external genitalia," Contrib Zool, vol. 81, no. 2, pp. 87-94, 2012.

27. C. R. Vilela and G. Bächli, "Taxonomic studies on Neotropical species of seven genera of Drosophilidae (Diptera)," Mitteilungen der Schweizerischen Entomol Gesellschaft, vol. 63, 1990.

28. M. Lang, M. Polihronakis Richmond, A. E. Acurio, T. A. Markow, and V. Orgogozo, "Radiation of the Drosophila nannoptera species group in Mexico," J Evol Biol, vol. 27, no. 3, pp. 575-584, 2014.

29. F. T. Rhebergen, V. Courtier-Orgogozo, J. Dumont, M. Schilthuizen, and M. Lang, "Drosophila pachea asymmetric lobes are part of a grasping device and stabilize one-sided mating," BMC Evol Biol, vol. 16, no. 1, p. 176, 2016.

30. C. G. Lamb, "The geometry of insect pairing," Proc R Soc B, vol. 94, 1922.

31. A. Acebes, M. Cobb, and J.-. F. Ferveur, "Species-specific effects of single sensillum ablation on mating position in Drosophila," J Exp Biol, vol. 206, 2003.

32. S. Jagadeeshan and R. S. Singh, "A time-sequence functional analysis of mating behaviour and genital coupling in Drosophila: role of cryptic female choice and male sex-drive in the evolution of male genitalia," J Evol Biol, vol. 19, no. 4, pp. 1058-1070, 2006.

33. A. L. Mattei, M. L. Riccio, F. W. Avila, and M. F. Wolfner, "Integrated 3D view of postmating responses by the Drosophila melanogaster female reproductive tract, obtained by micro-computed tomography scanning," Proc Natl Acad Sci U S A, vol. 112, 2015.

34. D. C. S. G. Oliveira, F. C. Almeida, P. M. O'Grady, M. A. Armella, R. DeSalle, and W. J. Etges, "Monophyly, divergence times, and evolution of host plant use inferred from a revised phylogeny of the Drosophila repleta species group," Mol Phylogenet Evol, vol. 64, no. 3, pp. 533-544, 2012.

35. A. Acurio, V. Rafael, D. Cespedes, and A. Ruiz, "Description of a new spottedthorax Drosophila (Diptera: Drosophilidae) Species and its evolutionary relationships inferred by a Cladistic analysis of morphological traits," Ann Entomol Soc Am, 106(6), 695-705, 2013.

36. S. Pitnick, T. A. Markow, and M. F. Riedy, "Transfer of ejaculate and incorporation of male-derived substances by females in the nannoptera species group (Diptera: Drosophilidae)," Evolution, vol. 45, no. 3, pp. 774-780, 1991.

37. S. Pitnick and T. A. Markow, "Male gametic strategies: sperm size, testes size, and the allocation of ejaculate among successive mates by the spermlimited fly Drosophila pachea and its relatives," Am Nat, vol. 143, no. 5, pp. 785-819, 1994.
38. B. Grant, "On the relationship between average copulation duration and insemination reaction in the genus Drosophila," Evolution, vol. 37, no. 4, pp. 854$856,1983$.

39. T. Markow and P. M. O'Grady, Drosophila, A guide to species identification and use. Amsterdam: Academic Press, Elsevier, 2005.

40. C. R. Vilela, "Occurrence of the Drosophila flavopilosa species group (Diptera, Drosophilidae) in the state of São Paulo (Brazil) with description of one new species," Revista Brasileira de Zoologia, vol. 2, no. 2, 1983.

41. C. R. Vilela and M. A. Q. R. Pereira, "Breeding sites of Neotropical Drosophilidae (Diptera). I. Living flowers of Cestrum schlechtendalii (Solanaceae)," Revista Brasileira de Entomologia, vol. 36, no. 2, pp. 475-482, 1992.

42. S. C. Vaz, C. R. Vilela, and A. B. Carvalho, "Two new species of Drosophila (Diptera, Drosophilidae) associated with inflorescences of Goeppertia monophylla (Marantaceae) in the city of São Paulo, state of São Paulo, Brazil," Revista Brasileira de Entomologia, vol. 62, no. 2, pp. 159-168, 2018.

43. A. D. Peñafiel-Vinueza and V. Rafael, "Five new species of Drosophila guarani group from the Andes of southern Ecuador (Diptera, Drosophilidae)," ZooKeys, vol. 781, pp. 141-163, 2018.

44. C. R. Vilela, G. Bächli, and M. C. Stensmyr, "Redescription of Drosophila endobranchia (Diptera, Drosophilidae), an aberrant member of the canalinea species group," Mitteilungen der Schweizerischen Entomologischen Gesellschaft, vol. 81, pp. 199-208, 2008

45. A. S. Hunter, "New Anthophilic Drosophila of Colombia," Ann Entomol Soc Am, vol. 72, no. 3, pp. 372-383, 1979.

46. A. S. Hunter, "High altitude flower-breeding Drosophila (Diptera: Drosophilidae)," Pan Pac Entomol, vol. 64, no. 4, pp. 299-312, 1988.

47. Owen R. Report on the archetype and homologies of the vertebrate skeleton. London: Printed by Richard and John E. Taylor; 1847.

48. S. Pitnick, T. A. Markow, and G. S. Spicer, "Delayed male maturity is a cost of producing large sperm in Drosophila," Proc Natl Acad Sci, vol. 92, no. 23, pp. 10614-10618, 1995.

49. S. Pitnick, T. Markow, and G. S. Spicer, "Evolution of multiple kinds of female sperm-storage organs in Drosophila," Evolution, vol. 53, no. 6, pp. 1804-1822, 1999

50. S. Pitnick and T. A. Markow, "Large-male advantages associated with costs of sperm production in Drosophila hydei, a species with giant sperm," Proc Natl Acad Sci, vol. 91, no. 20, p. 9277 LP-9279281, Sep. 1994.

51. S. Pitnick, G. S. Spicer, and T. A. Markow, "How long is a giant sperm?," Nature, vol. 375, p. 109, May 1995.

52. G. Arnqvist and L. Rowe, "Antagonistic coevolution between the sexes in a group of insects," Nature, vol. 415, 2002.

53. T. R. Birkhead and T. Pizzari, "Postcopulatory sexual selection," Nat Rev Genet, vol. 3, 2002.

54. T. Chapman, G. Arnqvist, J. Bangham, and L. Rowe, "Sexual conflict," Trends Ecol Evol, vol. 18, no. 1, pp. 41-47, 2003.

55. Eberhard WG, selection S, animal g. Harvard Un. Massachusetts: Cambridge; 1985

56. W. G. Eberhard, "Evolution of genitalia: theories, evidence, and new directions.", Genetica, vol. 138, no. 1, pp. 5-18, Oct. 2010.

57. M. Otronen and M. T. Siva-Jothy, "The effect of postcopulatory male behaviour on ejaculate distribution within the female sperm storage organs of the fly, Dryomyza anilis (Diptera : Dryomyzidae)," Behav Ecol Sociobiol, vol. 29, no. 1, pp. 33-37, 1991.

58. M. Otronen, "Sperm numbers, their storage and usage in the fly Dryomyza anilis," Proc R Soc Lond Ser B Biol Sci, vol. 264, no. 1382, p. 777 LP-777782, May 1997.

59. M. Otronen, "Male asymmetry and postcopulatory sexual selection in the fly Dryomyza anilis," Behav Ecol Sociobiol, vol. 42, no. 3, pp. 185-191, Mar. 1998.

60. A. Acurio, V. Rafael, and O. Dangles, "Biological invasions in the Amazonian tropical rain Forest: the case of Drosophilidae (Insecta, Diptera) in Ecuador, South America," Biotropica, vol. 42, no. 6, pp. 717-723, 2010.

61. M. Lang et al., "Mutations in the neverland gene turned Drosophila pachea into an obligate specialist Species," Science, vol. 337, no. 6102, p. 1658, 2012.

62. A. J. Drummond, M. A. Suchard, D. Xie, and A. Rambaut, "Bayesian phylogenetics with BEAUti and the BEAST 1.7," Mol Biol Evol, vol. 29, no. 8, pp. 1969-1973, 2012.

63. C. A. Russo, N. Takezaki, and M. Nei, "Molecular phylogeny and divergence times of drosophilid species.," Mol Biol Evol, vol. 12, no. 3, pp. 391-404, 1995.

64. H. T. Spieth, "Mating behavior within the genus Drosophila (Diptera)," Bull Am Museum Nat Hist, vol. 99, 1952 